started to police the activities of consultants very closely this could well be counter productive."

In the evidence to the inquiry many hoary old criticisms were wheeled out. There were allegations that private patients jumped the N.H.S. waiting list; that consultants neglected their N.H.S. duties in favour of their private practice and provided dual standards of care; that junior staffs received no reward for their help in looking after private patients; and that private patients were occasionally treated in N.H.S. beds, to instance only a few. The reported crossquestioning of witnesses before the subcommittee, however, gives the impression that, despite the trenchant and sweeping general criticisms in some of the written submissions, firm evidence of widespread abuse was elusive. Whether this is because patients do not know how to complain, or that hospital staff are reluctant to comment about consultants, or that evidence is scanty simply because abuse is far less frequent than the critics allege is debatable.

One thing is clear: the N.H.S. does not lose financially from allowing private practice on its territory. The report states ". . . everything including the costs of all staff is regarded as being covered by private patient charges. . . . private patients' fees to hospitals cover the services of junior doctors as whole-time employees of the Health Service." No doubt the patient paying $£ 122$ a week-apart from the private medical fees-for the privilege of a bed in a London teaching hospital might be forgiven for wondering whether he was supporting the whole hospital and not just his bed. But medicine is a very expensive commodity and this figure, carefully costed by the Department of Health, pales into insignificance compared with the charges in the U.S.A. or even in Western Europe.

The report, and more particularly the extensive evidence, has shown that there is little to support the noisy allegations about abuse of the Service. It publicizes once again the chronic problem of waiting lists, explodes a few longstanding myths, and since the system is working well, reasonably enough proposes no major changes. The conclusions and the recommendations are in line with the B.M.A.'s evidence ${ }^{2}$ to the inquiry, but these have been and will no doubt continue to be publicly attacked. ${ }^{3}$ However, if instead the critics-medical and political-pressed for an inquiry not into private practice but into N.H.S. financing and the allocation of priorities in the Service, then they would have the support of the whole medical profession. That sort of inquiry could make a really constructive contribution to the nation's health. 1 Fourth Report from the Expenditure Committee (Employment and

2 British Medical fournal, 4 September 1971, p. 549.

3 The Times, 30 March 1972, p. 3.

\section{Unplanned Pregnancy}

The growing pressure ${ }^{12}$ on the Government to include family planning within the N.H.S. has been given massive support this week by the report ${ }^{3}$ of the working party of the Royal College of Obstetricians and Gynaecologists headed by Sir John Peel. Its three major recommendations-a comprehensive contraceptive service within the N.H.S., more emphasis on teaching about contraception in medical schools, and facilities for male and female sterilization within the N.H.S. - will be widely supported; but it also makes important suggestions for future research and comments on present trends which deserve to be widely read.

The report presents statistics which show that illegitimate births are rising most rapidly among teenagers-one-third of such births are to women under the age of 20-and the working party was satisfied that premarital sexual intercourse among teenagers is becoming more prevalent, particularly in those under the age of 16 . No real evidence emerged of the effects of this early sexual activity-except for the physical and emotional stresses resulting from venereal disease or illegitimate pregnancy-but the working party clearly believed that the increasing incidence of sexual intercourse in the under-16s was undesirable. The report recommends that sexual education in schools should be given as part of health education, and it suggests that "properly designed follow-up studies should be started to try to determine the effects of educational school programmes" and that a joint committee should be established between the Departments of Health and Education and the Health Education Council.

This is only the first of a series of recommendations for research projects that should be established to provide reliable, objective evidence in fields which until now have been characterized by speculation and unsupported opinion. Other questions the report suggests need answering are the extent to which the availability of easy abortion is creating a tendency to disregard contraception and encouraging a more casual approach to sexual relationships; the difference if any in the outcome for the illegitimate child brought up by an unmarried mother and for the child brought up by one parent as a result of early divorce; and the relative significance of the reasons why contraception is still not universally acceptable and not more widely used.

The most controversial section of the report seems likely to be that dealing with the Abortion Act. The working party was told of the difficulties made for gynaecologists, nurses, and theatre staff within the N.H.S. by reason of the increased work load from consultations and terminations. "There is no doubt," says the report, "that for the vast majority of staff involved in abortion work, the work itself is sometimes distressing. . . . Consultants in N.H.S. hospitals have found that nursing staff, theatre staff, midwives and outpatient department staff not infrequently objected to this work." It goes on to acknowledge that there has been a recent marked change in public attitudes and that a large section of the public appears to think that the Act permits abortion on demand-or at least that every woman has the right "at the point where every reasonable avenue of support and relief has been explored in good faith on her behalf" to determine the outcome of her pregnancy. The working party recognized that attitudes of doctors vary widely on the basis of their personal, moral, and social convictions, and that consequently there are wide variations in the interpretation of the Act in different parts of the country.

These variations, the strain on the N.H.S. gynaecological services, and the comparatively large number of late terminations were all evidence of the defects in the working of the Act, but the working party had clearly had difficulty in reaching agreement on the best solution. The report suggests a need for some form of arbitration to resolve the present unsatisfactory situation in which the wide range of medical views on individual rights and responsibilities has led to a random process of opinion-taking in many cases. The 
working party offered no suggestions on how such an arbitration system could be established, and indeed it places the responsibility for clarification or amendment of the Act firmly on the Government. "If abortion on demand is intended," says the report, "then it is the responsibility of Government to indicate this and to amend the law and provide the services staffed by those willing to do this work."

What the report seems to imply is that the Government has two choices open to it. It can modify the Act clearly to exclude abortion for non-medical reasons, thus reducing the pressures on gynaecological services; or it can legalize abortion on demand, in which case the College would probably press for special units for all abortion work where there were no clear medical indications. "Clearly the proper staffing of special units would be essential and it was indicated to the Working Party that if special clinics were set up it would be necessary to ensure that there was full gynaecological, psychiatric, social and other services freely available to the patient," says the report, adding that even if special clinics were established within the N.H.S. there is no fundamental reason why they should be exempt from some form of payment.

The inquiry into the working of the Abortion Act under Mrs. Justice Lane ${ }^{4}$ will no doubt be reporting later this year, and it is likely to recommend some changes in the Act. This is an occasion when the Government must get its priorities right. Even if newer techniques such as using the vacuum aspiration catheter ${ }^{5}$ reduce morbidity from abortion, doctors will still support the view taken by the working party that prevention of unplanned pregnancy is far preferable to any of the possible alternative ways of dealing with it later. Unplanned and unwanted pregnancy should be a rare disaster in a society such as ours with ready access to medical advice. A determined campaign by the Government and the medical profession to make contraception understood, wanted, and available to all could well make revision of the Abortion Act quite unnecessary.

1 British Medical fournal, 1972, 1, 391

2 British Medical fournal, 1972, 1, 707

3 Unplanned Pregnancy. London, Royal College of Obstetricians and Gynaecologists, 1972, price $£ 1.00$.

4 British Medical fournal, 1971, 1, 512.

5 Lewis, S. C., Lal, S., Branch, B., and Beard, R. W., British Medical fournal, 1971, 4, 606

\section{Symposium on Glaucoma}

The publication of the First Cambridge Ophthalmological Symposium in the March issue of the British Fournal of Ophthalmology 1 on the subject of glaucoma is excuse enough to look for trends in the management of this disease. Held at St. John's College, Cambridge, in memory of Dr. Perrers Taylor, the symposium occupied two days, during which 21 papers were delivered and discussed.

Congenital glaucoma varies in severity and in its association with other ocular and somatic anomalies. Most cases fortunately respond to goniotomy, whereby the angle of the anterior chamber is opened by access across the anterior chamber by a special type of knife. When goniotomy fails the prognosis for congenital glaucoma remains poor in the long term. It would seem that the mechanism of acute or subacute glaucoma due to sudden block of the angle of the anterior chamber by the iris is well understood. It is a disease of clamant symptoms and responds well to peripheral iridectomy if the diagnosis is made early. In developed countries it should cease to be a major cause of blindness.

Glaucoma simplex is still the problem which defies solution. Insidious and symptomless in onset, it affects people in middle age. Genetically it is multifactorial, and the pattern of heredity is therefore not Mendelian though often familial. The cause of raised intraocular pressure would appear to lie in the trabecular meshwork on the inner side of the canal of Schlemm. The intimate nature of this obstruction is still something of a mystery, though intracellular vacuoles in the canal endothelium play some part in transport of aqueous from the anterior chamber into the canal in healthy eyes.

The introduction of the applanation tonometer and a method of measuring outflow by indentation tonometry were promising in the early 1960s as methods of assessment. Since then surveys have shown that raised pressure and low outflows are not synonymous with the syndrome of simple glaucoma. Tonography has proved a disappointing clinical test because prolonged pressure on the eye leads to the expression of both blood and aqueous, and the unknown proportion of each in any given test produces results which are unreliable as a measure of aqueous outflow. Provocative tests and steroid-induced hypertension have failed to produce clear diagnostic criteria in doubtful cases and have added little to our understanding of frank examples of the disease. What is still required is a clinically applicable quantitative method of determining the relationship between tension and loss of visual field in the individual patient. Meanwhile the time-honoured method of holding the intraocular pressure below $21 \mathrm{~mm} \mathrm{Hg}$, round the clock, if possible by medical treatment, still stands as the orthodox form of management.

Medical therapy includes miotics to contract the pupil. Because of the myopia induced they are particularly disabling for the patient who has an active accommodation. Epinephrine in combination with guanethidine bids fair to act as an alternative to miotic therapy because of the absence of side effects and the tension-lowering properties of the two drugs acting synkinetically. Surgery for glaucoma is also on the move, chiefly owing to the introduction of the operating microscope, which makes attacks on the canal of Schlemm itself feasible. Trabeculotomy, whereby the canal is entered and its inner wall is ruptured (or Barkan's membrane is ruptured) is now a popular procedure, particularly for congenital glaucoma when goniotomy fails. Trabeculectomy, wherein part of the canal is excised so that its open ends are exposed to the anterior chamber, is gaining adherents. It functions possibly as a drainage operation with an exit well away from the limbus, but this site in itself has distinct advantages particularly in the avoidance of a cystic avascular bleb and the risks of postoperative infection.

The striking feature of the symposium was the renewed interest in the optic nerve-head-its blood supply, its vascular response to raised intraocular pressure, its appearance in the fluorescein angiogram, and its varying configuration in health and disease. It was even suggested by one contributor that changes at the disc head are of prime importance as a guide to diagnosis and progression. The obsession with ocular hydrodynamics which filled the minds of most ophthalmologists interested in glaucoma for many years appears to be lifting and an atmosphere of release pervaded a stimulating meeting.

\footnotetext{
1 British fourmal of Ophthalmology, 1972, 56, Pt. 3.
} 